\title{
Effective surface functionalization of fumed silica with NBR telechelic oligomer for high-voltage polyolefin-based dielectric composites
}

\author{
R. Anyszka ${ }^{1}$, X. $\mathrm{He}^{1}$, A. Mahtabani ${ }^{1}$, W. Dierkes ${ }^{1} \&$ A. Blume \\ ${ }^{1}$ Department of Mechanics of Solids, Surfaces and Systems (MS3), Faculty of Engineering Technology, Chair of Elastomer \\ Technology and Engineering, University of Twente, Enschede, The Netherlands \\ Email address of the corresponding author r.p.anyszka@utwente.nl
}

\begin{abstract}
In this study an effective surface functionalization of fumed nano-silica for dielectric insulation composites is developed. A three step modification procedure was applied: 1. Silanization of the silica surface with (3-glycidoxypropyl)trimethoxysilane (GOPTMS); 2. Grafting of an acrylonitrile-butadiene telechelic oligomer terminated with two carboxylic acid groups (o-NBR); 3. Hydrogenation of the unsaturated polybutadiene segments for better compatibilization with the saturated polyolefin matrices and for higher dielectric performance.
\end{abstract}

The deposition of the coupling system was monitored by thermogravimetric analysis (TGA) revealing $6.4 \mathrm{wt}$. \% of GOPTMS and $13.6 \mathrm{wt}$. \% of o-NBR bond to the silica, resulting in an exceptionally high total deposition (20.0 wt. \%). The oNBR grafting was analyzed qualitatively by Fourier transform infrared spectroscopy (FTIR) showing successful deposition of o-NBR and effective hydrogenation.

The silica modified according to this procedure is a promising functional nano-filler for high-voltage insulation composites allowing improved dispersion and distribution in polyolefine matrices and therefore enhancing their electrical properties.

\section{Introduction}

Recent progress in diversification of electric energy generation sources and development of smart grids has triggered the need of designing innovative materials for high-voltage current transmission applications.

Thermoplastic polyolefins, such as polyethylene (PE), polypropylene (PP) or poly(ethylene-co-octene) (POE), exhibit good dielectric and insulating properties, which make them ideal candidates for high voltage applications. Moreover, they show very good processability, mechanical properties and aging resistance. However, these polymers are not entirely free from drawbacks: for example, the melting temperature of $\mathrm{PE}$ is relatively low, which necessitates cross-linking (XLPE) for high-voltage applications. Under service conditions, a local temperature rise could be dangerously close to the melting temperature of non-cross-linked PE. This results in inability of effective material recycling of the XLPE insulator after its use [1]. PP exhibits a significantly higher melting temperature than PE $\left(\sim 160{ }^{\circ} \mathrm{C}\right.$ versus $\sim 110{ }^{\circ} \mathrm{C}$, respectively), however its elasticity is limited necessitating its copolymerization or blending with more flexible polyolefins (like POE) in order to achieve a satisfactory level of elasticity.

Incorporation of nano-particle fillers into polymer matrix in order to improve their electrical properties is reported in literature [2-4]. R. C. Smith et al, showed that incorporation of nano-fillers consisting of particles of a size lower than $100 \mathrm{~nm}$ results in a significant improvement of the dielectric strength and voltage endurance of the polymer composites [5]. This, results from increasing of the interfacial area formed between the polymer matrix and the nano-filler surface area [6], but also from altering the interphase properties by incorporating specific chemical groups attached to the nano-filler surface (in particular polar moieties) [2]. In order to improve the dispersion and distribution of nano-fillers in the polyolefin matrix, a surface treatment of the filler is applied that reduces the physicochemical incompatibility between the polar nano-filler and the non-polar matrix. The nano-filler/polymer compatibilization effectiveness is very important, as poor dispersion and distribution of the filler can lead to counterproductive results like an early electrical breakdown of the dielectric composite [7]. Therefore, new approaches leading to effective nano-filler surface modifications are widely needed and developed.

In this study we present a novel approach for an effective surface functionalization of fumed silica for polyolefin-based nano-dielectric composite preparation. Such a surface functionalization of fumed silica is a challenging task, since its surface contains a significantly lower amount of silanol groups. To overcome this disadvantage, a three step procedure was applied: 1. Formation of oligomerized silane layer on the silica surface - this is the crucial step allowing high yield grafting as it introduces a high amount of ethoxy groups reactive towards the carboxy-terminated oligomer; 2 . grafting of telechelic oligomer macromolecules onto the silane layer; 3 hydrogenation of the oligomer for better compatibilization with the saturated polyolefine matrix.

\section{Materials \& Methods}

Fumed silica Aerosil 200 was obtained from Evonik Industries, Germany. (3-Glycidoxypropyl)trimethoxysilane (GOPTMS; $98 \%$ purity), tripropylamine (98\% purity) and ptoluenesulfonyl hydrazide (98\% purity) were purchased from ABCR GmbH, Germany. Dicarboxy terminated acrylonitrilebutadiene oligomer (o-NBR; 8-12 wt. \% of bonded acrylonitrile, 
$\mathrm{M}_{\mathrm{n}} \sim 3800 \mathrm{~g} / \mathrm{mol}$ ) was originated from Sigma-Aldrich Merck, Germany. Technical grade toluene was obtained from BOOM B. V., The Netherlands.

In the first step, the silica was silanized with (3glycidoxypropyl)trimethoxysilane (GOPTMS). $10 \mathrm{~g}$ of the silica with $1 \mathrm{ml}$ of GOPTMS and $100 \mu \mathrm{l}$ of an acidic catalyst were placed in three-neck round bottom glass flask equipped with thermometer and water cooler. At last, $300 \mathrm{ml}$ of the toluene was added to make a stable suspension. The flask was immersed in a silicone oil filled heating bath, which was placed on a magnetic heater/stirrer. A teflon-covered magnetic stirring bar was placed inside the flask to stir the suspension vigorously $(500 \mathrm{rpm})$. The ingredients were heated up to $110^{\circ} \mathrm{C}$ in an air atmosphere and stirred for 14 hours. Afterwards, the silica was removed from the flask and filtered with the help of a low-pressure pump and rinsed two times with fresh toluene.

In the second step, the silica silanized in the first step was once again placed in a similarly equipped round bottom flask with $3 \mathrm{~g}$ of o-NBR. The mixture was treated under similar conditions as step 1 for 14 hours. Afterwards the modified silica was removed from the flask, filtered, rinsed with toluene and placed into a laboratory oven heated up to $120{ }^{\circ} \mathrm{C}$ for 6 hours. Then the modified silica was purified from ungrafted o-NBR by a Soxhlet extraction with boiling toluene for 14 hours.

In the third, final step, $1.5 \mathrm{~g}$ of the o-NBR grafted silica was hydrogenated with a mixture of $1.35 \mathrm{~g}$ of $\mathrm{p}$-toluenesulfonyl hydrazide and $0.85 \mathrm{~g}$ of tripropylamine. All the ingredients were placed in the previously used round bottom flask equipped with thermometer, cooler and this time also a nitrogen inlet unit to implement an inert atmosphere for the reaction. The flask was filled with toluene and stirred with a magnetic bar for 8 hours in inert nitrogen atmosphere at $105{ }^{\circ} \mathrm{C}$. Afterwards the modified silica was purified by Soxhlet extraction with toluene for 14 hours.

The amount of the deposited silane and grafted o-NBR were measured by means of a TA Instruments 550 thermogravimeter (TGA). The samples were heated from room temperature to $650{ }^{\circ} \mathrm{C}$ under synthetic air atmosphere with a heating rate of $20{ }^{\circ} \mathrm{C} / \mathrm{min}$. From this test the samples mass loss in function of temperature (TGA) and their derivatives (DTGA) were obtained. The o-NBR grafting results and the hydrogenation effect were qualitatively analyzed by Fourier transform infrared spectrometry (FTIR) using a Perkin Elmer Spectrum 100 machine equipped with an attenuated total reflectance (ATR) unit. The scanned wavelength spectrum was within $650-4000$ $\mathrm{cm}^{-1}$. The resulting spectrum obtained was an average of 12 measurements.

\section{Results \& Discussion}

The approach of silica surface modification to improve the compatibility with polyolefine matrices bases on the methodology proposed by Z. Huang et al. [8]. This method comprises the following reactions: 1 . Silanization of a surface with (3-glycidoxypropyl)trimethoxysilane (Figure 1); 2. Addition reaction between the epoxy ring from the silane and carboxylic acid groups positioned at both ends of a telechelic oligomer molecule (Figure 2). In order to improve the compatibility between the grafted oligomer and a polyolefin matrix and to improve the dielectric properties of the composites, hydrogenation of the oligomer backbone was performed (Figure 3).

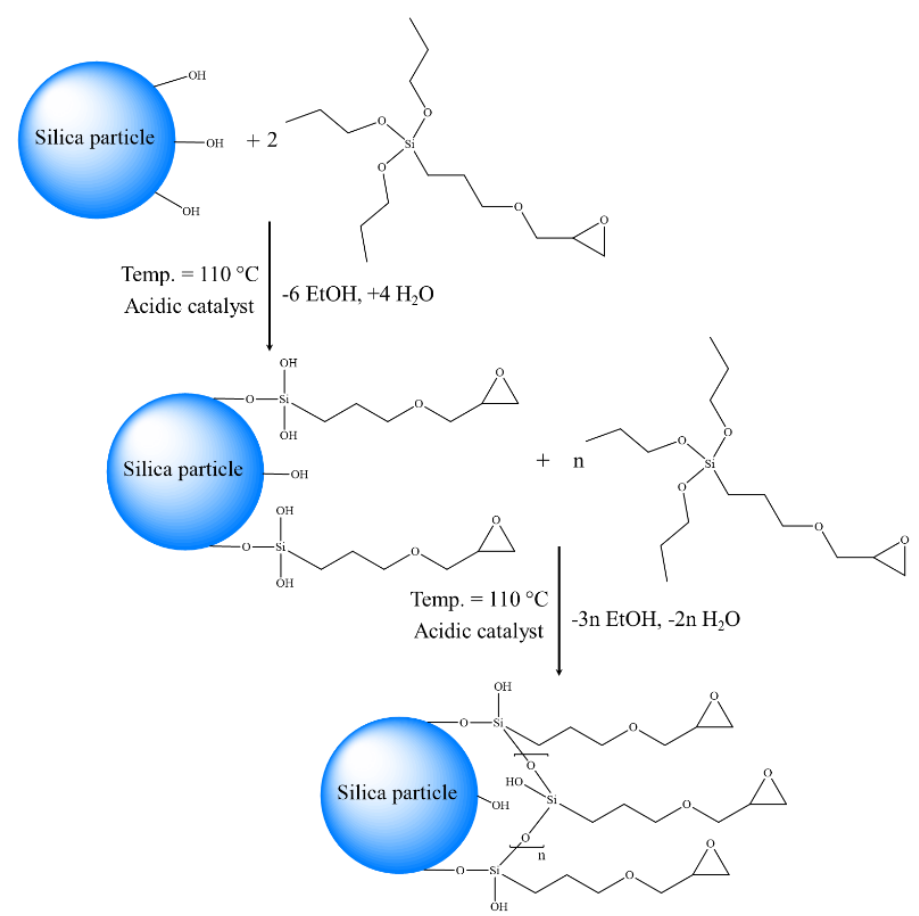

Figure 1. Scheme of silica surface silanization with GOPTMS.

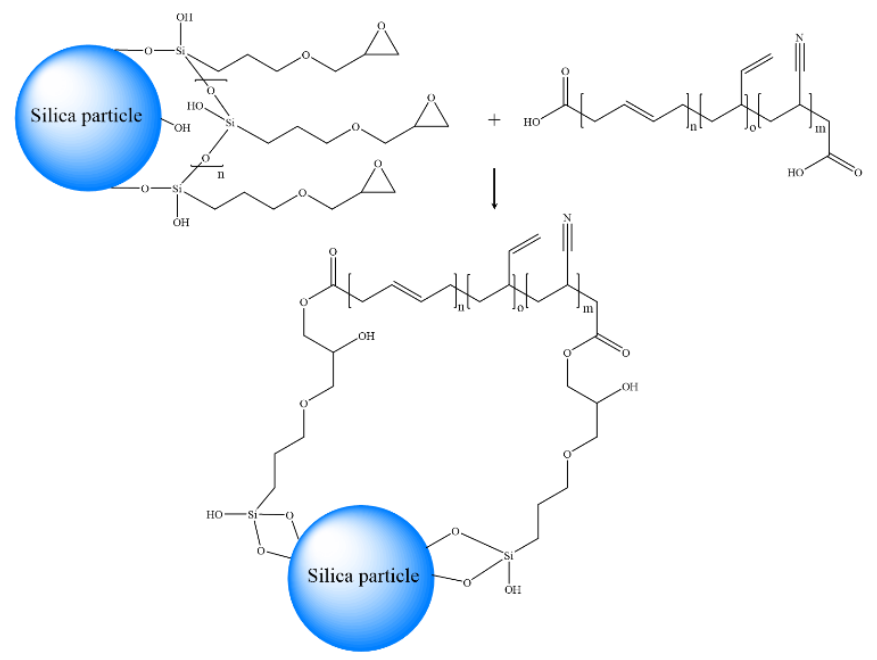

Figure 2. Scheme of o-NBR grafting onto the silica surface. 

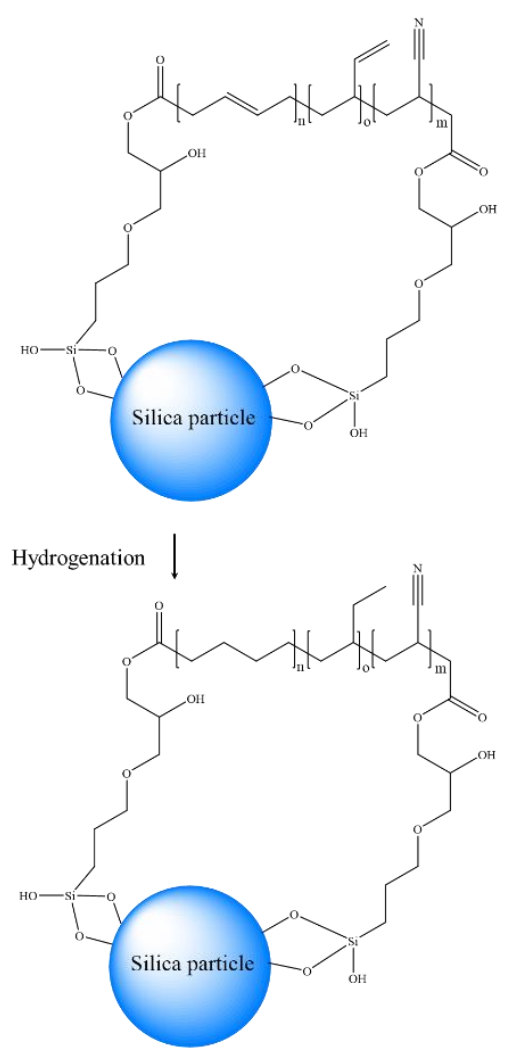

Figure 3. Scheme of hydrogenation of the unsaturated carboncarbon bonds.

The first two steps of the modification were monitored by TGA showing the amount of the coupling agent chemically anchored to the silica surface (Figure 4). The way that fumed silica is produced results in a very low moisture content, which makes it promising for application in dielectric nanocomposites as a functional filler. The mass loss at $650{ }^{\circ} \mathrm{C}$ measured for the reference Aerosil 200 sample was only $0.6 \%$, whereas the modified silica samples exhibit $6.4 \%$ and $20.0 \%$ of mass loss after silanization and o-NBR grafting respectively. This shows a very high effectiveness of the modification, not only in comparison to commercially available modified fumed silicas (up to $4.5 \%$ of deposited coupling agent), but even to more sophisticated approaches, for example living polymerization of polyethylene on a silica surface [9].

The reason behind the difficulties in surface modification of fumed silica is its significantly lower silanol group content on the surface, in comparison to precipitated silica. Besides, it has a lower bonded water amount that serves as a catalyst for the silanization reaction. In order to overcome these drawbacks, we deposited a layer of an epoxy-containing silane on the surface of the silica. The silane contains three ethoxy groups that facilitate condensation with the silanol groups from silica and with each other, leading to formation of oligomeric segments bonded to the silica surface. The oligomeric segments contain a significant amount of epoxy groups that react with carboxyl groups from the telechelic o-NBR allowing dense deposition of the o-NBR macromolecules on the silica surface.

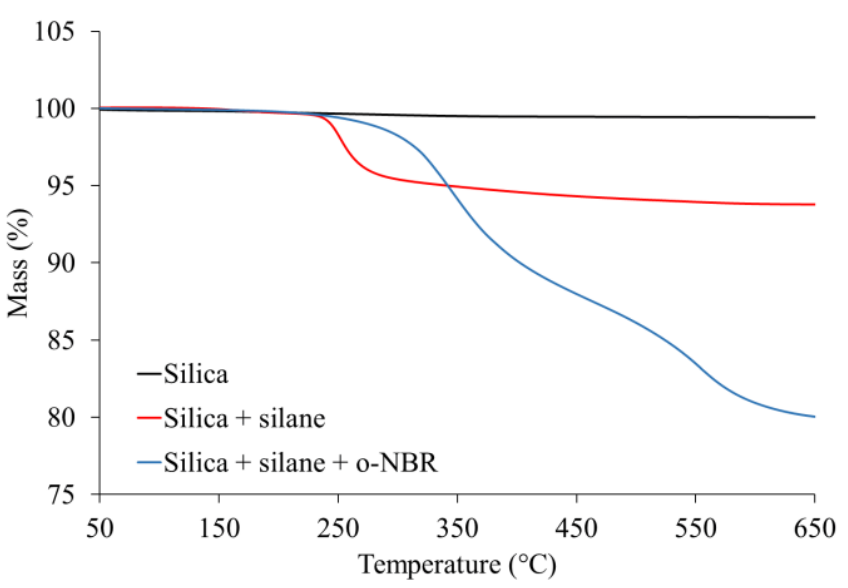

Figure 4. TGA curves of the silica before and after modification.

Furthermore, the o-NBR grafting resulted in an increase of thermal stability of the organic layer on the silica surface (Table 1). The onset temperature of thermal decomposition $\left(\mathrm{T}_{01}\right)$ increased from $243.7{ }^{\circ} \mathrm{C}$ to $274.7{ }^{\circ} \mathrm{C}$ after o-NBR grafting. Besides, the temperature of the first highest decomposition rate (T1) increased after o-NBR grafting from $254.4{ }^{\circ} \mathrm{C}$ to $349.4{ }^{\circ} \mathrm{C}$ showing a significant enhancement of the thermal stability of the organic layer (Figure 5). This is most likely an effect of the additional heat treatment performed after the o-NBR grafting resulting in post-condensation of the remaining reactive silanol groups of GOPTMS reacting with each other or with the silanol groups on the silica surface [10]. The more dense cross-liked structure formed after the post-condensation is expected to exhibits higher thermal stability because of a higher content of strong covalent bonds present in the same molar volume of the silane layer.

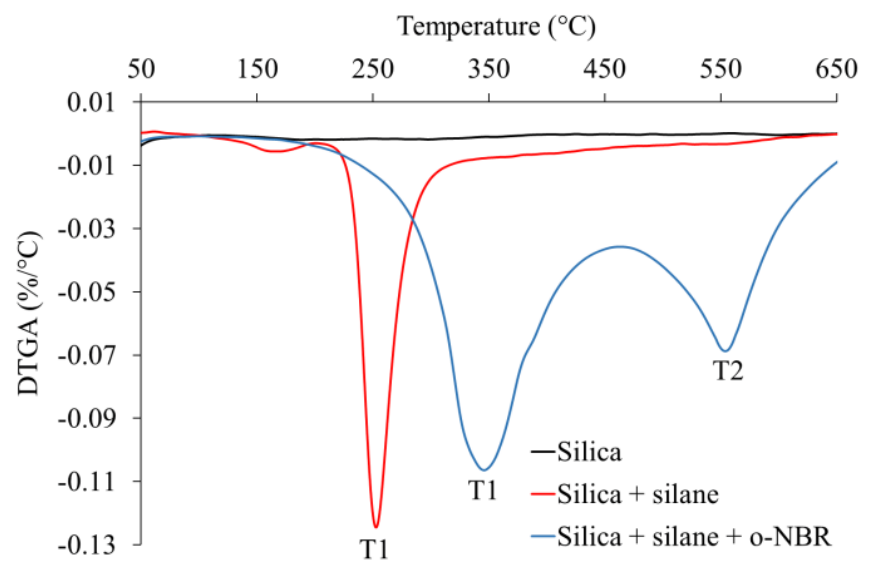

Figure 5. DTGA curves of the silica before and after modification.

The silica grafted with o-NBR exhibits two step kinetics of thermal decomposition of the deposited organic layer. The high value of the temperature of the second highest decomposition rate $\left(\mathrm{T} 2=557.4{ }^{\circ} \mathrm{C}\right)$ observed for the o-NBR-grafted silane suggests formation of a carbonaceous residue from o-NBR during the thermal decomposition. The acrylonitrile mers present in the o-NBR macromolecular backbone are considered 
to be able to trigger carbonization of NBR-based composites $[11,12]$. Under synthetic air atmosphere the carbonaceous char burns out completely leaving only silica as non-flammable residue (Figure 4).

Table 1. Parameters of thermal stability of the surface modified silica samples: $\mathrm{T}_{01}$ - onset temperature of thermal decomposition (temperature of $1 \%$ mass loss); $\mathrm{T} 1$ - temperature of the first highest decomposition rate; $\mathrm{T} 2$ - temperature of the second highest decomposition rate.

\begin{tabular}{lccc}
\hline \multirow{2}{*}{ Parameter } & \multicolumn{3}{c}{ Sample description } \\
\cline { 2 - 4 } & Silica & Silica + silane & $\begin{array}{c}\text { Silica + silane } \\
+\boldsymbol{+ o - N B R}\end{array}$ \\
\hline $\mathrm{T}_{01}\left({ }^{\circ} \mathrm{C}\right)$ & - & 243.7 & 274.7 \\
$\mathrm{~T} 1\left({ }^{\circ} \mathrm{C}\right)$ & - & 254.4 & 349.4 \\
$\mathrm{~T} 2\left({ }^{\circ} \mathrm{C}\right)$ & - & - & 557.4 \\
Residue at $650{ }^{\circ} \mathrm{C}(\%)$ & 99.4 & 93.8 & 80.0 \\
\hline
\end{tabular}

In order to confirm the o-NBR presence on the silica surface, FTIR spectra were taken (Figure 6). The reference silica does not show any specific bands of organic compounds. But after grafting of the o-NBR via GOPTMS, four characteristic bands appear: bands at $2857 \mathrm{~cm}^{-1}$ and $2929 \mathrm{~cm}^{-1}$ originate from $>\mathrm{CH}_{2}$ symmetric and antisymmetric stretching respectively; the band at $911 \mathrm{~cm}^{-1}$ from $=\mathrm{CH}_{2}$ vinyl groups and the band at $969 \mathrm{~cm}^{-1}$ originates from $=\mathrm{C}-\mathrm{H}$ bending from butadiene mers. The presence of the former bands at $2857 \mathrm{~cm}^{-1}$ and $2929 \mathrm{~cm}^{-1}$ are associated with saturated hydrocarbon chains, whereas the latter $\left(911 \mathrm{~cm}^{-1}, 969 \mathrm{~cm}^{-1}\right)$ come from unsaturated chain fragments.

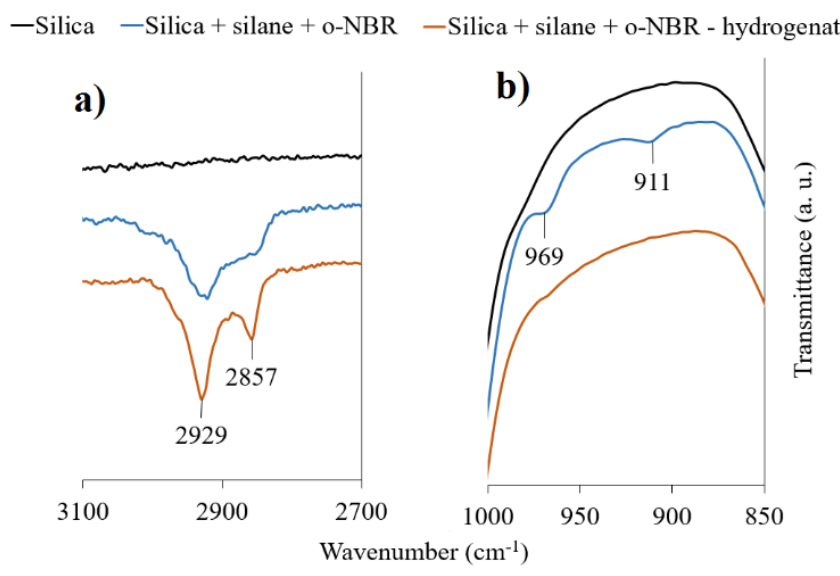

Figure 6. FTIR spectra of the silica before modification, after o-NBR grafting and after hydrogenation: focus on two spectra ranges: a) $2700-3100 \mathrm{~cm}^{-1}$ and b) $850-1000 \mathrm{~cm}^{-1}$.

The hydrogenation effectiveness is confirmed by disappearance of the bands from unsaturated chain fragments $\left(911 \mathrm{~cm}^{-1}\right.$ and $\left.969 \mathrm{~cm}^{-1}\right)$ with simultaneously increased intensity of the bands at $2857 \mathrm{~cm}^{-1}$ and $2929 \mathrm{~cm}^{-1}$ (Figure 6).

Successful grafting and hydrogenation of a significant amount of o-NBR chains containing 8-12 wt.\% of bonded acrylonitrile should result in compatibilization of the silica with the polyolefin matrix in comparison to the currently applied coupling agents. This is caused by the higher degree of miscibility between hydrogenated polybutadiene segments with saturated hydrocarbon macromolecules of the polyolefins commonly used as high voltage cable cover insulators.
Simultaneously, incorporation of nitrogen-containing polar acrylonitrile mers is expected to alter the charge trapping properties of the insulation composites by improving both, the dielectric breakdown strength and the space charge distribution as is suggested in literature [2].

\section{Conclusions}

A novel approach for an effective surface modification of fumed silica was presented. A straight-forward three step modification procedure resulted in deposition of a significant amount $(20.0 \%)$ of the organic coupling system. The silica with the grafted and hydrogenated o-NBR oligomer exhibits two main functionalities: 1. High compatibility with polyolefine matrices like XLPE, PP and POE (88-92 wt.\% of hydrogenated polybutadiene segments); 2 . Altered electrical properties of the nano-dielectric composites by introduction of nitrogencontaining polar groups into the polymer/nano-filler interphase (8-12 wt.\% of acrylonitrile segments present in o-NBR).

Application of this nano-filler for polyolefine-based insulating composites is expected to result in a significant improvement of their dielectric performance.

\section{Acknowledgments}

This project has received funding from the European Union's Horizon 2020 research and innovation programme under grant agreement No 720858 .

The authors would like to thank the ECIU Researcher Mobility Fund for supporting this research work.

The authors also would like to thank Evonik Industries for providing a free silica sample.

\section{References}

[1] Y. Sekiguchi, N. Ohkawa, H. Nojo and S. Hashimoto, "Development of recycling technology of XLPE", JICABLE'07, 2007.

[2] D. Ma, T. A. Hugener, R. W. Siegel, A. Christerson, E. Martensson, C. Onneby and L. S. Schadler, "Influence of nanoparticle surface modification on the electrical behaviour of polyethylene nanocomposites", IOP Nanotechnology, vol. 16, no. 6, 2005, pp. 724-731.

[3] X. Huang, P. Jiang and Y. Yin, "Nanoparticle surface modification induced space charge suppression in linear low density polyethylene", Applied Physics Letters, vol. 95, no. 24, 2009, p. 242905.

[4] X. Huang, Y. Zheng, P. Jiang, and Y. Yin, "Influence of nanoparticle surface treatment on the electrical properties of cycloaliphatic epoxy nanocomposites", IEEE Transactions on Dielectrics and Electrical Insulation, vol. 17, no. 2, 2010, pp. 635-643.

[5] R. C. Smith, C. Liang, M. Landry, J. K. Nelson, and L. S. Schadler, "The mechanisms leading to the useful electrical properties of polymer nanodielectrics", IEEE Transactions on Dielectrics and Electrical Insulation, vol. 15, no. 1, 2008, pp. 187-196.

[6] T. J. Lewis, "Nanometric dielectrics", IEEE Transactions on Dielectrics and Electrical Insulation, vol. 1, no. 5, 1994, pp. 812-825.

[7] T. P. Schuman, S. Siddabattuni, O. Cox, and F. Dogan, "Improved dielectric breakdown strength of covalently-bonded interface polymer-particle nanocomposites", Composite Interfaces, vol. 17, no. 8, 2010, pp. 719-731.

[8] Z. Huang, H. Ji, J.W. Mays and M.D. Dadmun, "Understanding the grafting of telechelic polymers on a solid substrate to form loops", Macromolecules, vol. 43, no. 3, 2008, pp. 1009-1018.

[9] P. Xiang, K. Petrie, M. Kontopoulou, Z. Ye and R. Subramanian, “Tuning structural parameters of polyethylene brushes on silica nanoparticles in surface-initiated ethylene "living" polymerization and effects on silica dispersion in a polyolefin matrix", Polymer Chemistry, vol. 4, no. 5., 2013, pp. 1381-1395. 
[10] A. M. Tiefenthaler and M. W. Urban, "Thermal stability of silane coupling agents on Nextel fibres", Composites, vol. 20, no. 2, 1989, pp. 145-150.

[11] G. Gao, Z. Zhang, Y. Zheng and Z. Jin, "Effect of fiber orientation angle on thermal degradation and ablative properties of short-fiber reinforced EPDM/NBR rubber composites", Polymer Composites, vol. 31, no. 7, 2010, pp. 1223-1231.

[12]D. I. Chukov, A. A. Stepashkin, A. I. Salimon, S. D. Kaloshkin and I. S. Pyatov,"Mechanical properties and chemical resistance of new composites for oil pump impellers", Applied Sciences, vol. 8, no. 5, 2018, pp. 750. 